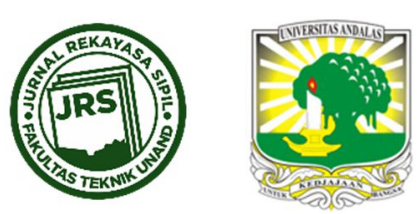

\title{
QUANTITY TAKE-OFF BERBASIS BUILDING INFORMATION MODELING (BIM) STUDI KASUS: GEDUNG BAPPEDA PADANG
}

\author{
RUDY FERIAL ${ }^{1 *}$, BENNY HIDAYAT ${ }^{1}$, REGINA CITRA PESELA ${ }^{1}$, DARWIZAL \\ DAOED $^{1}$
}

${ }^{1}$ Jurusan Teknik Sipil, Fakultas Teknik, Universitas Andalas, Padang, Indonesia

*Corresponding author: $ه$ rudyferial@eng.unand.ac.id

Naskah diterima : 04 Oktober 2021. Disetujui: 22 Desember 2021

\begin{abstract}
ABSTRAK
Penelitian ini bertujuan untuk mengetahui penggunaan software Autodesk ${ }^{\circledR}$ Revit $^{\circledR}$ dan Autodesk $^{\circledR}$ Naviswork ${ }^{\circledR}$ Manage untuk pekerjaan Quantity Take-Off dan menganalisa perbedaan hasil perhitungan QTO berbasis Building Information Modeling dan QTO manual. Studi kasus penelitian adalah Data Perencanaan Gedung Bappeda Kota Padang. Penelitian dilakukan dengan membuat BIM Model Gedung tersebut berdasarkan Detail Engineering Design. Selanjutnya dilakukan review model dengan tools Clash Detection pada Autodesk ${ }^{\circledR}$ Naviswork ${ }^{\circledR}$ Manage, selanjutnya BIM Model tersebut dihitung volumenya. Hasil perhitungannya kemudian dibandingkan dan dianalisa. Hasil penelitian menunjukan bahwa ada beberapa kelebihan dan kekurangan dalam penggunaan software tersebut untuk pekerjaan QTO. Item pekerjaan arsitektur yang dihitung sebanyak 146 item pekerjaan, ditemukan 88 pekerjaan sesuai dengan volume manual, 4 pekerjaan hampir sesuai dengan volume manual, 10 pekerjaan tidak sesuai dengan volume manual dan 44 pekerjaan tidak dapat dihitung. Item pekerjaan stuktur yang dihitung sebanyak 122 item pekerjaan, ditemukan 113 pekerjaan sesuai dengan volume manual, 2 pekerjaan hampir sesuai dengan volume manual, 6 pekerjaan tidak sesuai dengan volume manual dan 1 pekerjaan tidak dapat dihitung.
\end{abstract}

Kata kunci : qto, bim, revit, naviswork

\section{PENDAHULUAN}

Pelaksanaan proyek konstruksi dipengaruhi oleh banyak faktor salah satunya adalah faktor biaya (Firdaus et al., 2020). Biaya pelaksanaan proyek konstruksi didapatkan dari perhitungan Rencana Anggaran Biaya (RAB) proyek tersebut. Secara umum, RAB dipengaruhi oleh kuantitas (volume) pekerjaan dan harga satuan pekerjaan (HSP).

Quantity Take-Off (QTO) adalah pekerjaan perhitungan secara detail volume material dan pekerja yang dibutuhkan untuk menyelesaikan suatu proyek konstruksi (Wikipedia, 2018). Pekerjaan QTO harus dilakukan secara akurat dan konsisten. Biasanya pekerjaan QTO dilakukan secara manual, yaitu dengan cara menghitung dimensi dari elemen-elemen 
bangunan seperti luas, volume, panjang dan lain-lain. QTO yang dikerjakan secara manual seringkali menimbulkan kesalahan-kesalahan seperti kesalahan pembacaan dimensi, penginputan data dan lain-lain . Kesalahan pada waktu menghitung bisa saja terjadi seperti: kesalahan aritmatik, pembagian, angka dibelakang koma, lupa memasukan jenis material, dan lain sebagainya (Soedrajat, 1984).

Salah satu pekerjaan yang dapat dikerjakan dengan BIM adalah pekerjaan Quantity TakeOff (QTO). Sebagian besar software yang berbasis BIM memiliki fitur untuk melakukan perhitungan quantity (volume) dari data geometri yang ada pada model tersebut. Quantity Take-Off (QTO) yang berbasis BIM memiliki keluaran (output) yang lebih sederhana, lebih akurat dan lebih detail daripada perhitungan QTO secara manual.

Software BIM yang populer adalah Autodesk ${ }^{\circledR}$ Revit $^{\circledR}$ dan Autodesk ${ }^{\circledR}$ Naviswork ${ }^{\circledR}$ Manage. Penggunaan software Autodesk ${ }^{\circledR}$ Revit ${ }^{\circledR}$ dan Autodesk ${ }^{\circledR}$ Naviswork ${ }^{\circledR}$ Manage untuk pekerjaan QTO masih jarang dilakukan di Indonesia. Sehingga dalam penelitian diformulasikan sebuah pertanyaan riset, seperti apa akurasi software BIM tersebut dalam QTO dibandingkan dengan metoda manual?

Tujuan dari penelitian ini adalah menggunakan software Autodesk ${ }^{\circledR}$ Revit $^{\circledR}$ dan Autodesk ${ }^{\circledR}$ Naviswork ${ }^{\circledR}$ Manage untuk pekerjaan QTO, serta menganalisa perbedaan hasil perhitungan QTO berbasis Building Information Modeling dengan perhitungan QTO secara manual. Agar pembahasan penelitian semakin fokus dan terukur, maka perlu dilakukan pembatasan masalah. Pembatasan yang dilakukan antara lain bahawa data proyek yang digunakan adalah kumpulan data Perencanaan Proyek Gedung Bappeda Kota Padang Tahun 2018 yang terdiri dari Dokumen Design Engineering Drawing (DED) dan Bill of Quantity (BOQ). Kemudian hasil perhitungan manual dalam pekerjaan QTO diambil dari data BOQ Perencanaan Proyek Gedung Bappeda Kota Padang Tahun 2018, dan pekerjaan yang dihitung adalah pekerjaan arsitektur dan pekerjaan struktur dari Perencanaan Proyek Gedung Bappeda Kota Padang Tahun 2018.

\subsection{Building Information Modeling (BIM)}

Istilah Building Information Model pertama kali muncul dalam sebuah makalah tahun 1992 oleh G.A van Neverdeen dan F.P Tolman. Namun, istilah Building Information Model dan Building Information Modeling masih belum populer digunakan hingga ketika seorang Analis Industri yang bernama Jerry Laiserin, membahas suatu teknologi desain terbaru yang siap untuk menggantikan teknologi Computer Aided Design (CAD) (PUPR, 2018).

Building Information Modeling (BIM) adalah proses dan cara bekerja dengan memanfaatkan kombinasi data-data digital yang berhubungan dengan bangunan atau proyek konstruksi. BIM sudah mulai digunakan untuk memenuhi kebutuhan industri konstruksi sejak lama yaitu kemampuan pengukuran, review dan analisis kinerja proyek konstruksi, terutama dalam penggabungan informasi - informasi digital yang ada. Sehingga dengan menerapkan metode BIM, baik developer, konsultan maupun kontraktor mampu menghemat waktu pengerjaan, biaya yang dikeluarkan serta tenaga kerja yang dibutuhkan. Beberapa tingkat implementasi BIM yang berlaku di berbagai negara dapat dilihat pada Gambar 1. 


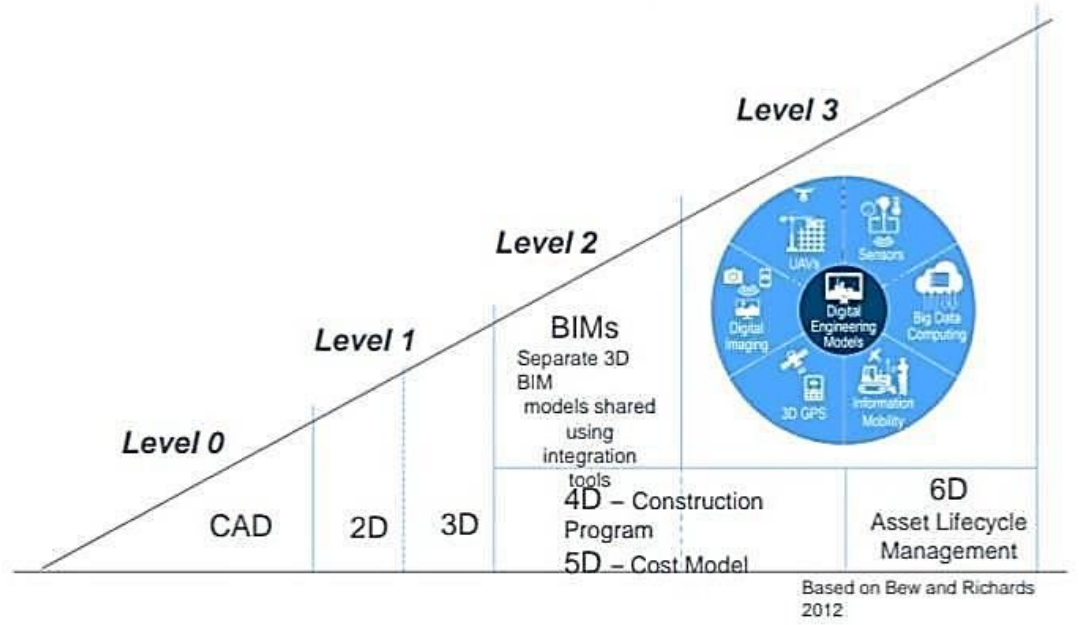

Gambar 1. Tingkat Implementasi BIM (Bew \& Richards, 2008)

\subsection{Building Information Model (BIM Model)}

Building Information Model adalah suatu model bangunan yang mewakili sebagian atau keseluruhan informasi tentang suatu bangunan (Smith \& Tardif, 2009). Building Information Model tidak hanya diartikan sebagai sebuah model 3D saja (B1M, 2015). Seperti yang dikatakan oleh Kimon Onuma, seorang arsitek dan juga software developer, sebuah data spreadsheet yang berisi data spasial juga dapat dikatakan sebagai Building Information Model. Sebuah data dapat dikatakan sebagai Building Information Model karena memiliki informasi yang terstruktur dan dapat kita olah nantinya dengan software-software yang mendukung hal tersebut.

Uraian pekerjaan dalam sebuah proyek didefenisikan dalam WBS. WBS merupakan uraian dari seluruh kegiatan yang akan dilaksanakan untuk dapat mentransformasikan gambar konstruksi beserta seluruh persyaratannya agar menjadi bangunan secara fisik yang sesuai dengan persyaratan yang telah ditetapkan (Badan Pembinaan Konstruksi Kemen. PU., 2014).

Pembuatan BIM model bisa dilakukan dengan berbagai aplikasi, diantaranya adalah Autodesk ${ }^{\circledR}$ Revit ${ }^{\circledR}$ dan Autodesk ${ }^{\circledR}$ Naviswork ${ }^{\circledR}$ Manage (Gambar 2). Autodesk ${ }^{\circledR}$ Revit $^{\circledR}$ adalah software building information modeling yang ditujukan untuk para arsitek, insinyur struktur, insinyur MEP, desainer dan kontraktor (Autodesk, 2020). Software ini digunakan untuk melakukan desain dan dokumentasi suatu proyek konstruksi. Software ini menghasilkan informasi seperti desain bangunan, kuantitas, fase proyek dan lain-lain. Sementara Autodesk ${ }^{\circledR}$ Naviswork ${ }^{\circledR}$ Manage adalah software yang didesain untuk membantu para pihak yang bekerja di industri konstruksi. Software ini bekerja dengan mengkombinasikan 3D BIM Model dengan berbagai format informasi lainnya kedalam satu tempat sehingga memudahkan untuk melakukan review desain, koordinasi, melakukan simulasi dan presentasi (Stachoni, 2011). Autodesk ${ }^{\circledR}$ Naviswork $^{\circledR}$ Manage memiliki teknologi untuk mengoptimasi model 3D menjadi lebih ringan. Software ini juga memiliki banyak fitur yang memudahkan kita melakukan analisa dan review desain yaitu Clash Detective, TimeLiner, Animator, Scripter dan Presenter. Meskipun tidak bisa digunakan untuk membuat objek namun karena memiliki kemampuan untuk mengolah file model yang berukuran besar yang cukup baik, software ini sering digunakan untuk mengkoordinasikan pekerjaan-pekerjaan dari berbagai disiplin seperti arsitektur, struktur, elektrikal dan lainlain. 


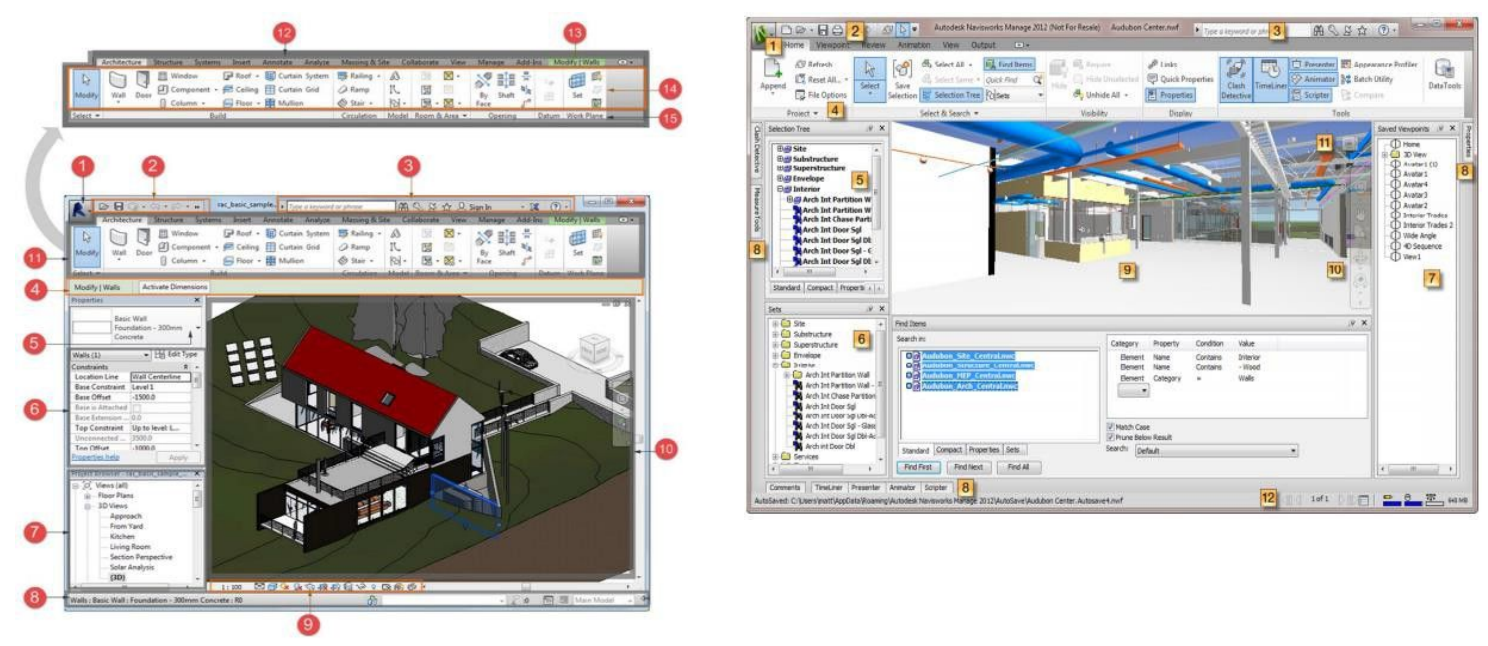

Gambar 2. User Interface dari Autodesk ${ }^{\circledR}$ Revit $^{\circledR}$ dan Autodesk ${ }^{\circledR}$ Naviswork ${ }^{\circledR}$

\section{METODA PENELITIAN}

Dalam penelitian ini dilakukan pemodelan gedung dan perhitungan quantity take-off. Gedung yang dibuat BIM Model-nya adalah Gedung Bappeda Kota Padang. Gedung ini merupakan gedung perkantoran dua lantai yang berada di Jalan Bagindo Aziz Chan, Kota Padang, Provinsi Sumatera Barat. Secara garis besar kerangka penelitian ini dapat digambarkan sesuai diagram alir pada Gambar 3 berikut.
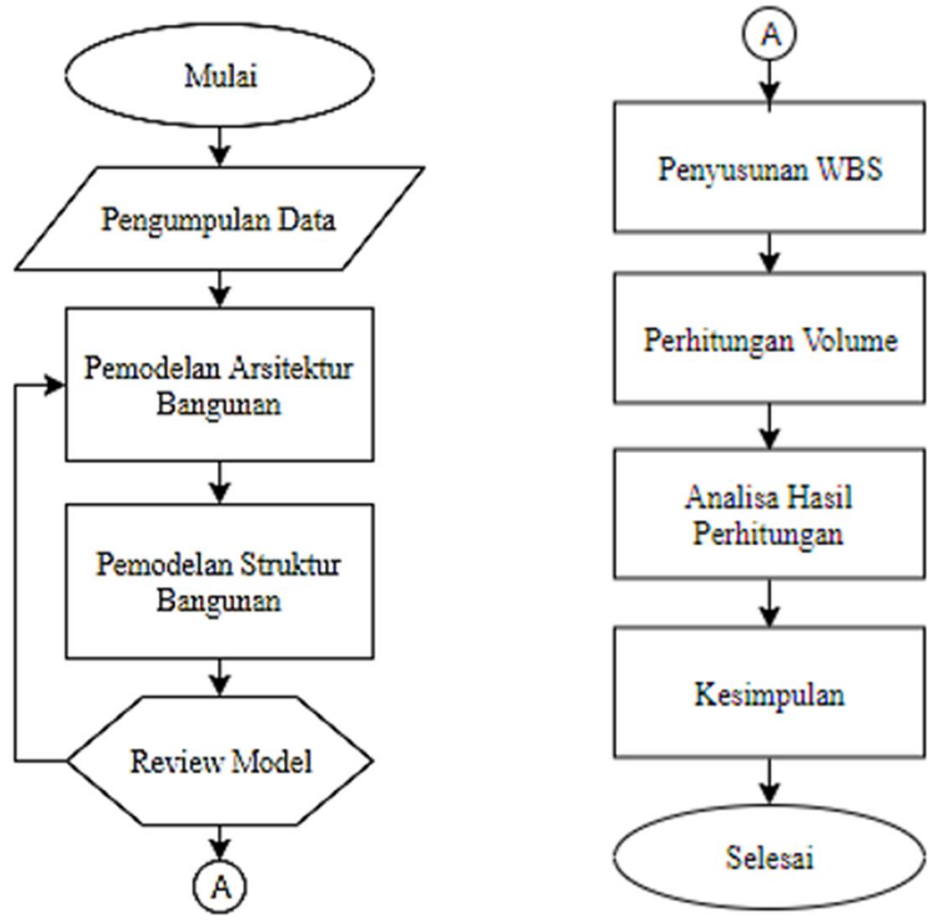

Gambar 3. Diagram alir penelitian 
Pengumpulan data dilakukan berupa pengumpulan gambar Detail Engineering Design (DED) Perencanaan Proyek Gedung Bappeda Kota Padang dan Bill of Quantity (BOQ) Pekerjaan Arsitektur dan Struktur Proyek Gedung Bappeda Kota Padang

Kemudian dilakukan pemodelan bangunan dibuat dengan bantuan software Autodesk ${ }^{\circledR}$ Revit ${ }^{\circledR}$ 2016. Pemodelan ini dibagi menjadi 2 yaitu model arsitektur dan model struktur. Seluruh model dibuat berdasarkan gambar Detail Engineering Design (DED) yang telah ada. Review model dilakukan dengan model arsitektur dan struktur bangunan digabungkan di Autodesk ${ }^{\circledR}$ Naviswork ${ }^{\circledR}$ Manage 2016 untuk selanjutnya dilakukan analisis clash detection, apabila ada clash model struktur dengan model arsitektur maka model tersebut diperbaiki dulu. Apabila tidak ada clash, maka lanjut ketahap berikutnya.

Sebelum melakukan perhitungan volume pekerjaan, terlebih dahulu disusun WBS-nya berdasarkan item catalog dari Uniformat atau template yang telah disediakan. Dengan menyusun WBS diketahui item-item pekerjaan apa saja yang akan kita hitung kuantitasnya. Perhitungan volume pekerjaan dihitung dengan bantuan quantification tools yang ada di software Autodesk ${ }^{\circledR}$ Naviswork ${ }^{\circledR}$ Manage 2016. Hasil perhitungan akan diolah lagi kedalam format yang sudah disediakan. Hasil perhitungan volume pekerjaan dilakukan dengan software Autodesk ${ }^{\circledR}$ Naviswork ${ }^{\circledR}$ Manage 2016, kemudian dibandingkan dengan volume pekerjaan hasil perhitungan manual. Kesimpulan diambil dengan mengetahui perbedaan hasil perhitungan QTO yang berbasis BIM dalam kasus ini menggunakan software Autodesk ${ }^{\circledR}$ Revit $^{\circledR}$ dan Autodesk ${ }^{\circledR}$ Naviswork ${ }^{\circledR}$ Manage dengan QTO yang berdasarkan perhitungan manual.

\section{HASIL DAN PEMBAHASAN}

\subsection{Pemodelan Bangunan}

Pemodelan bangunan dilakukan dengan memanfaatkan data dari gambar DED. Elemenelemen arsitektur bangunan yang dimodelkan meliputi dinding, pintu, jendela, atap, railing tangga, dan seluruh elemen-elemen pekerjaan arsitektur lainnya. Elemen-elemen bangunan yang dimodelkan meliputi pondasi, balok sloof, kolom, plat lantai, balok, tangga dan seluruh elemen-elemen pekerjaan struktur lainnya Model bangunan dapat dilihat pada Gambar 4 dan Gambar 5.
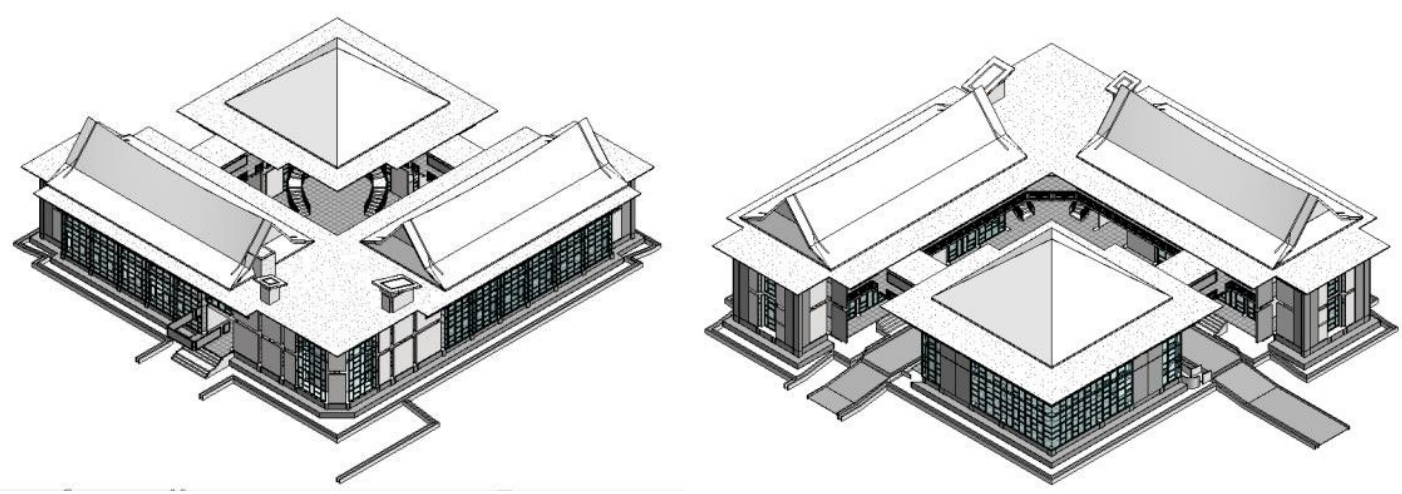

Gambar 4. Model Arsitektur Bangunan 


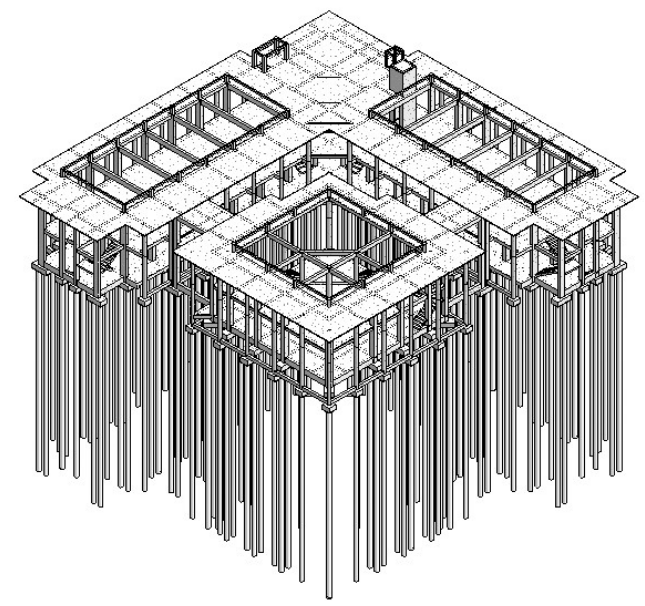

Gambar 5. Model Struktur Bangunan

\subsubsection{Review Model}

Review Model dibutuhkan untuk memastikan kesesuaian posisi antar masing-masing elemen- elemen bangunan agar tidak saling bersenggolan (clash) karena model arsitektur dan model struktur dibuat pada file yang berbeda. Proses review model ini dilakukan terlebih dahulu secara manual dengan menggabungkan (link model) file tersebut pada software Autodesk ${ }^{\circledR}$ Naviswork $^{\circledR}$ Manage dengan bantuan fitur Clash Detection pada software tersebut.
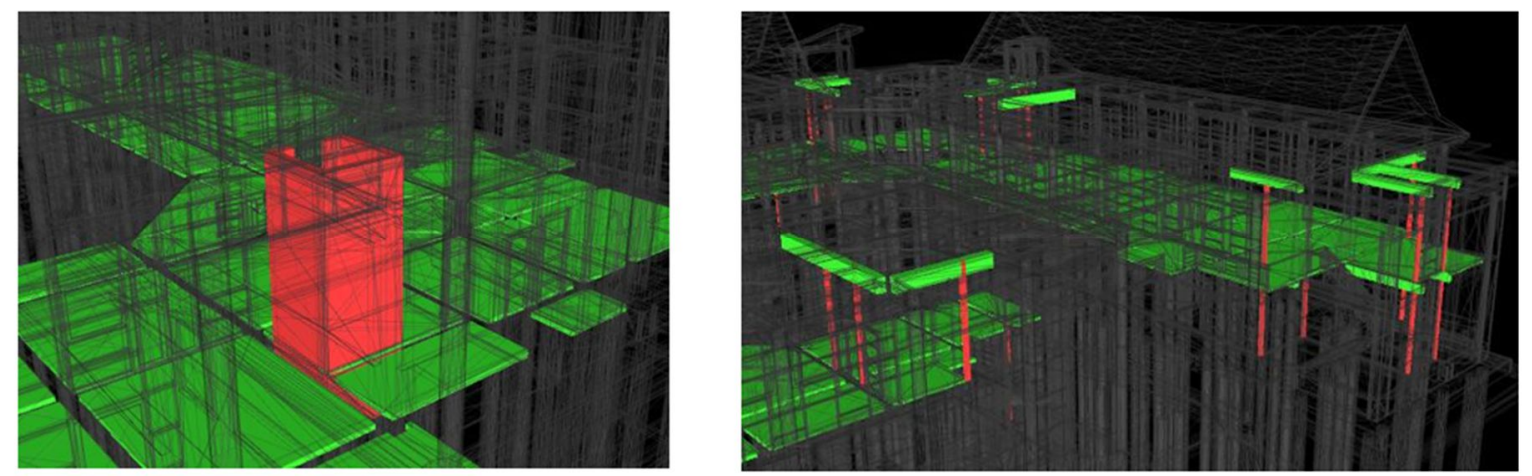

Gambar 6. Clash antara elemen Model Arsitektur dan Model Struktur

Clash yang diperiksa adalah seluruh elemen Model Arsitektur dengan seluruh elemen Model Struktur. Selanjutnya BIM Model tersebut diperbaiki kembali sesuai data clash yang ditemukan. Contoh clash yang ditemukan dapat dilihat pada Gambar 6.

\subsubsection{Penyusunan Work Breakdown Structure}

Fitur software Autodesk ${ }^{\circledR}$ Naviswork ${ }^{\circledR}$ Manage yang akan digunakan adalah Quantification Tools. Namun untuk menggunakannya terlebih dahulu disusun Work Breakdown Structure (WBS) sesuai dengan Bill of Quantity yang sudah didapatkan dari Proyek Gedung Bappeda Kota Padang. Penyusunan WBS dilakukan dengan menggunakan catalog template yang disediakan oleh Autodesk. 


\subsection{Perhitungan Volume}

Proses perhitungan volume akan diurut berdasarkan WBS ini. Setiap data yang didapatkan merupakan data yang ada pada elemen-elemen masing-masing objek pada BIM Model tersebut. Data yang didapatkan cukup bervariasi seperti panjang, luas, volume, berat dan lain-lain. Namun data yang diambil disesuaikan dengan Bill of Quantity per item pekerjaannya. Misalnya perhitungan volume dinding di BOQ menggunakan satuan $\mathrm{m} 2$ maka data yang diambil juga merupakan satuan m2 juga.

Pada software Autodesk ${ }^{\circledR}$ Naviswork ${ }^{\circledR}$ Manage, seluruh objek yang telah dihitung akan berubah warnanya menjadi sesuai dengan item pekerjaannya (Gambar 7). Sehingga dengan fitur ini akan meminimalisir kemungkinan untuk kesalahan perhitungan dua kali.

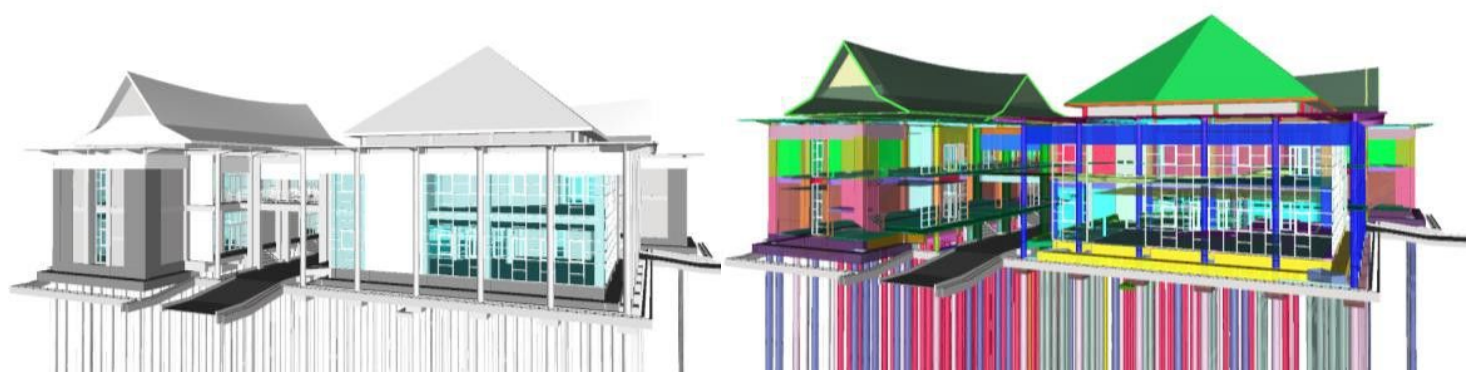

Gambar 7. BIM Model Gedung Sebelum dan Sesudah Perhitungan Volume

\subsubsection{Perhitungan Volume Model Arsitektur dan Struktur}

Seluruh model gedung dihitung volumenya sesuai WBS yang telah dibuat sebelumnya. Salah satu objek arsitektur yang dihitung adalah dinding dan plafond seperti dapat dilihat di Gambar 8 dan salah satu objek struktur yang dihitung adalah kolom dan plat lantai seperti dapat dilihat di Gambar 9.

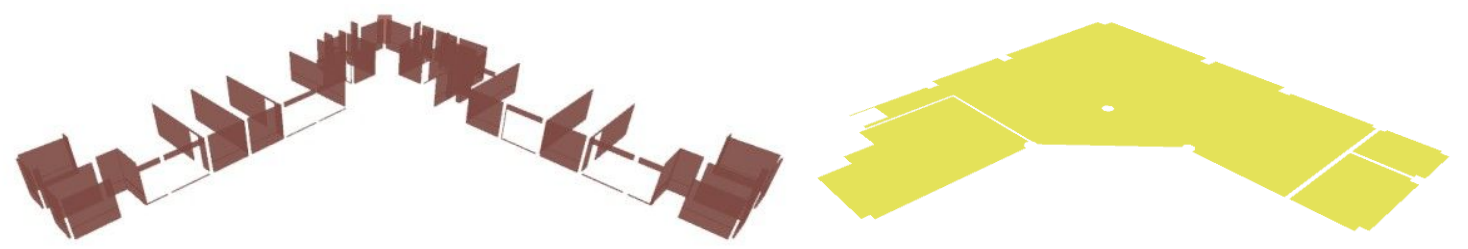

Gambar 8. Perhitungan Volume Dinding dan Plafond

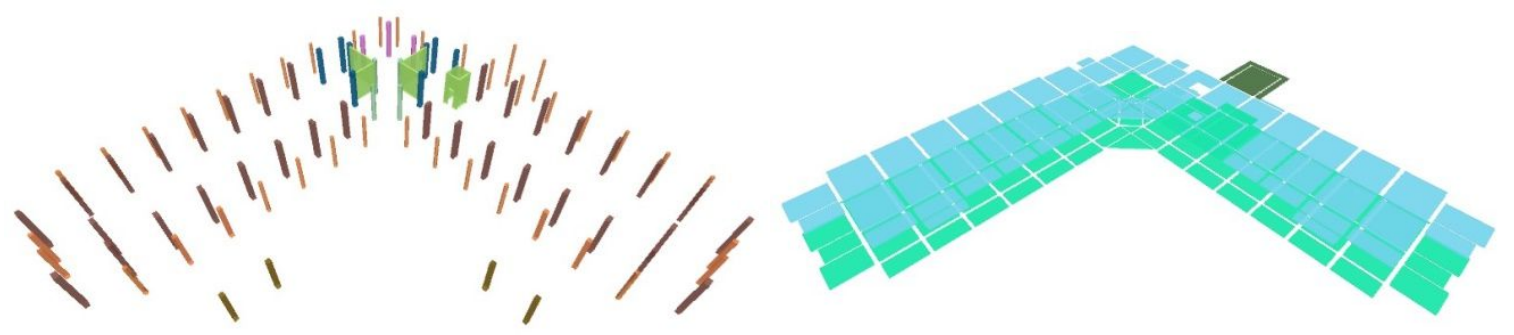

Gambar 9. Perhitungan Volume Kolom dan Plat Lantai 


\subsubsection{Export Hasil Perhitungan Volume}

Setelah seluruh item pekerjaan dihitung seluruhnya, data tersebut di-export kedalam format .XLS sehingga nanti bisa dibandingkan dengan perhitungan BOQ secara manual (Gambar 10). Export Data dengan menggunakan tools Quantifications > Export Quantities to Excel.

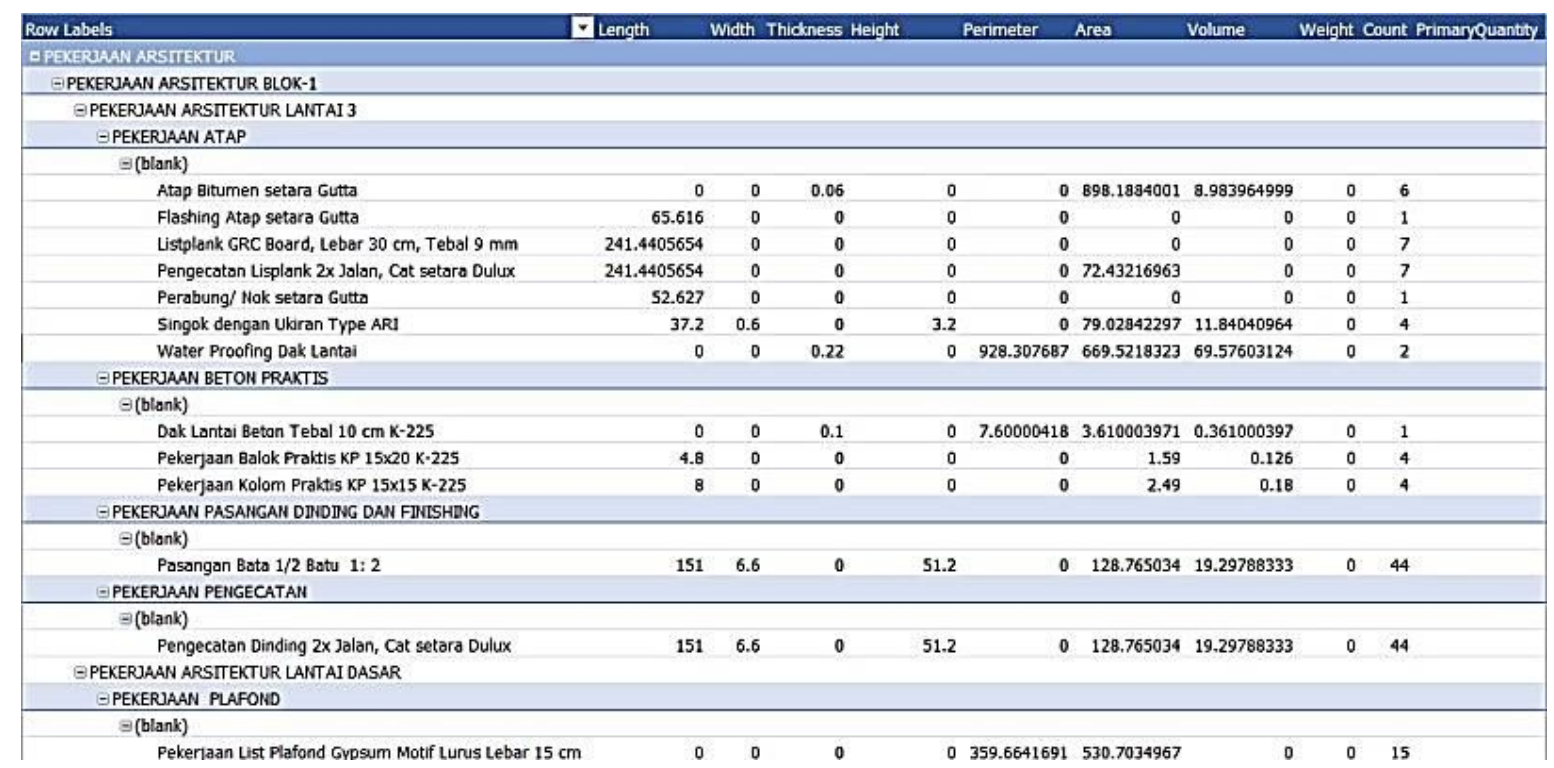

Gambar 10. Hasil Export Data ke Excel

\subsection{Analisa Hasil Perhitungan}

Seluruh hasil perhitungan volume dengan menggunakan Autodesk ${ }^{\circledR}$ Naviswork ${ }^{\circledR}$ Manage dibandingkan dengan perhitungan volume sebelumnya. Selain itu untuk mempermudah analisa, data tersebut diubah menjadi bentuk persentase (\%). Persentase (\%) tersebut kemudian diklasifikasikan sesuai Tabel 1. Seluruh pekerjaan yang diklasifikasikan "Tidak Sesuai" dan "Hampir Sesuai" dianalisa penyebab perbedaannya.

Tabel 1. Klasifikasi Perbandingan Volume Manual dan Volume BIM

\begin{tabular}{cc}
\hline Persentase (\%) & Klasifikasi \\
\hline$>140$ & Tidak Sesuai \\
\hline $120 \geq \mathrm{x} \geq 140$ & Hampir Sesuai \\
\hline $80<\mathrm{x}<120$ & Sesuai \\
\hline $60 \leq \mathrm{x} \leq 80$ & Hampir Sesuai \\
\hline$<60$ & Tidak Sesuai \\
\hline
\end{tabular}

\subsubsection{Perhitungan volume pekerjaan arsitektur}

Hasil perbandingan volume manual dan volume BIM pada pekerjaan arsitektur dapat dilihat pada Tabel 2. Item pekerjaan yang tidak dapat dihitung merupakan pekerjaan railing tangga, item pekerjaan kusen pintu dan jendela tidak bisa dihitung. Hal ini karena item pekerjaan tersebut pada Volume Manual menggunakan satuan "unit" yang artinya menganggap objek tersebut sebagai satu kesatuan sedangkan software Autodesk ${ }^{\circledR}$ Naviswork ${ }^{\circledR}$ Manage menganggap objek-objek tersebut tidak sebagai satu kesatuan melainkan terdiri dari berbagai objek. Contohnya pada elemen jendela seperti Gambar 11. 
Tabel 2. Perbandingan Item Pekerjaan Arsitektur

\begin{tabular}{lc}
\hline \multicolumn{1}{c}{ Klasifikasi } & Jumlah Pekerjaan \\
\hline Sesuai & 88 \\
\hline Hampir Sesuai & 4 \\
\hline Tidak Sesuai & 10 \\
\hline Tidak Dapat Dihitung & 44 \\
\hline
\end{tabular}

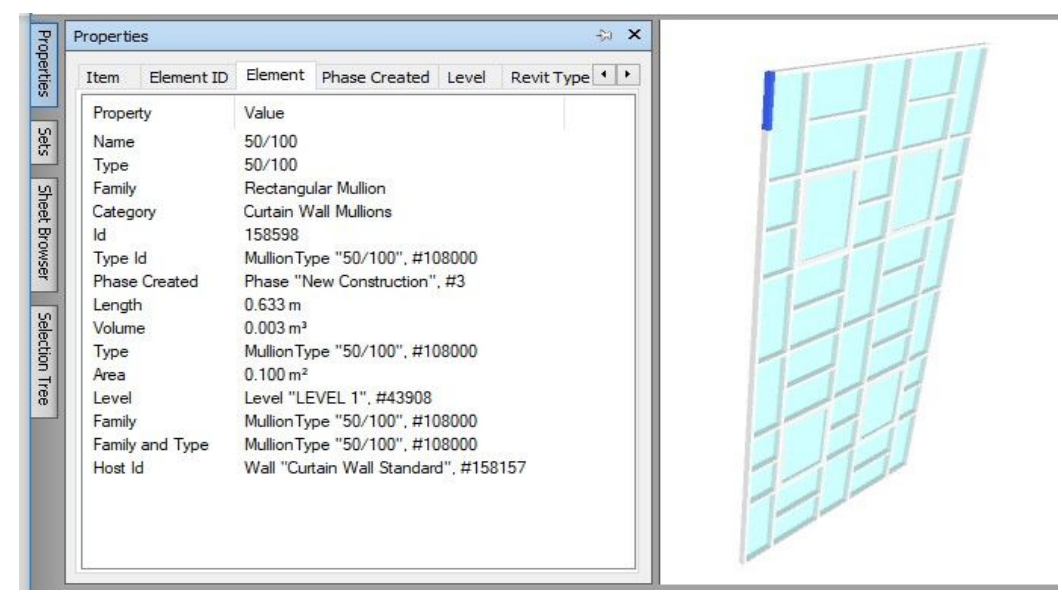

Gambar 11. Elemen Jendela pada BIM Model

Item pekerjaan lain yang diklasifikasikan "hampir sesuai" dan "tidak sesuai" disebabkan oleh banyak hal. Salah satunya adalah kesalahan menghitung jumlah objek pada gambar DED, kesalahan input data dan kesalahan perhitungan. Contohnya pada Pekerjaan Ornamen Ukiran type UK4 (Gambar 12 dan Gambar 13) volume manual memiliki hasil $22.80 \mathrm{~m} 2$ dan volume BIM memiliki hasil $2.28 \mathrm{~m} 2$. Pada gambar DED, ukiran type UK4 berjumlah 2 Unit. Jika dihitung secara manual, luas 2 unit ukiran tersebut adalah $2.28 \mathrm{~m} 2$. Ukiran type UK4 pada software Autodesk ${ }^{\circledR}$ Naviswork ${ }^{\circledR}$ Manage juga berjumlah 2 unit. Dapat disimpulkan perhitungan dengan menggunakan BIM lebih akurat.
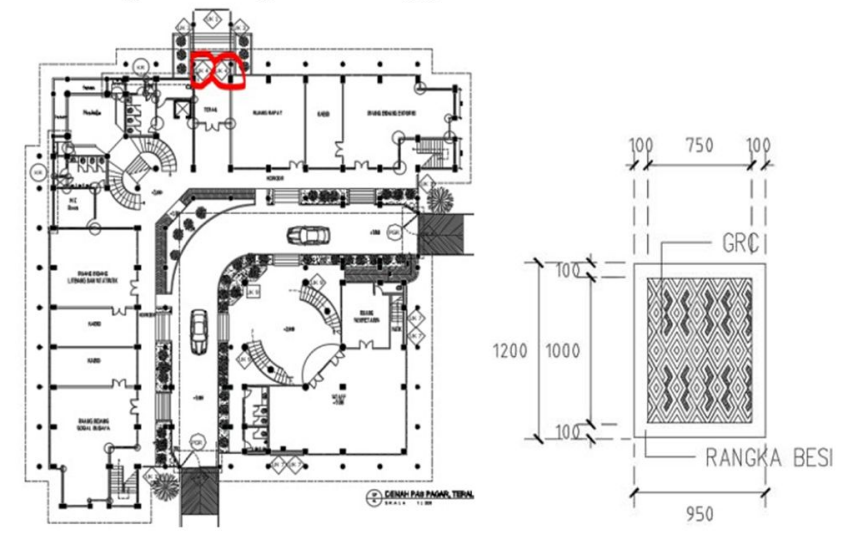

Gambar 12. Denah Lokasi dan Detail Ukiran type UK4 pada gambar DED

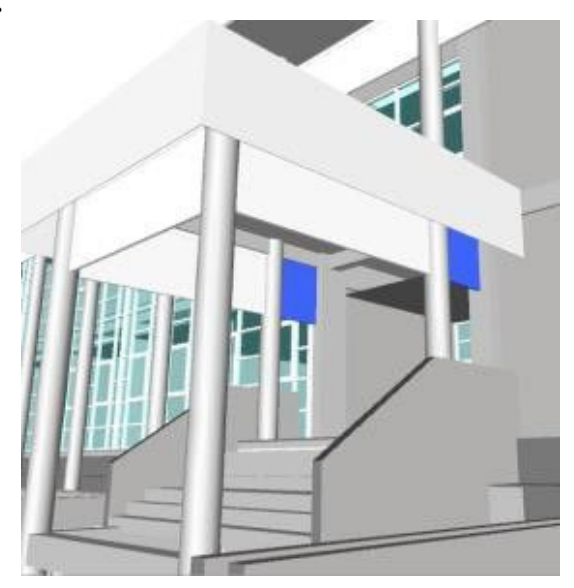

Gambar 13. Ukiran type UK4 pada BIM Model

\subsubsection{Perhitungan volume pekerjaan struktur}

Hasil perbandingan volume manual dan volume BIM pada pekerjaan struktur dapat dilihat pada Tabel 3. 
Tabel 3. Perbandingan Item Pekerjaan Struktur

\begin{tabular}{lc}
\hline \multicolumn{1}{c}{ Klasifikasi } & Jumlah Pekerjaan \\
\hline Sesuai & 113 \\
\hline Hampir Sesuai & 2 \\
\hline Tidak Sesuai & 6 \\
\hline Tidak Dapat Dihitung & 1 \\
\hline
\end{tabular}

Item pekerjaan yang tidak dapat dihitung merupakan pekerjaan Pekerjaan Pile Cap Tipe PC-4A (100/200) tidak bisa dihitung karena Pile Cap tipe PC-4A tidak ditemukan pada gambar DED. Item pekerjaan lain yang diklasifikasikan "hampir sesuai" dan "tidak sesuai" disebabkan oleh banyak hal. Salah satunya adalah kesalahan menghitung jumlah objek pada gambar DED, kesalahan input data dan kesalahan perhitungan.

Contohnya ada Pekerjaan Kolom K 1 (40/70) (Gambar 14, Gambar 15) volume manual memiliki hasil $23.52 \mathrm{~m} 3$ dan volume BIM memiliki hasil 44.74 m3. Dengan menggunakan rumus volume sederhana diperkirakan volume manual menghitung kolom K1 sebanyak 24 kolom, sedangkan pada gambar DED kolom K1 ada 34 kolom.
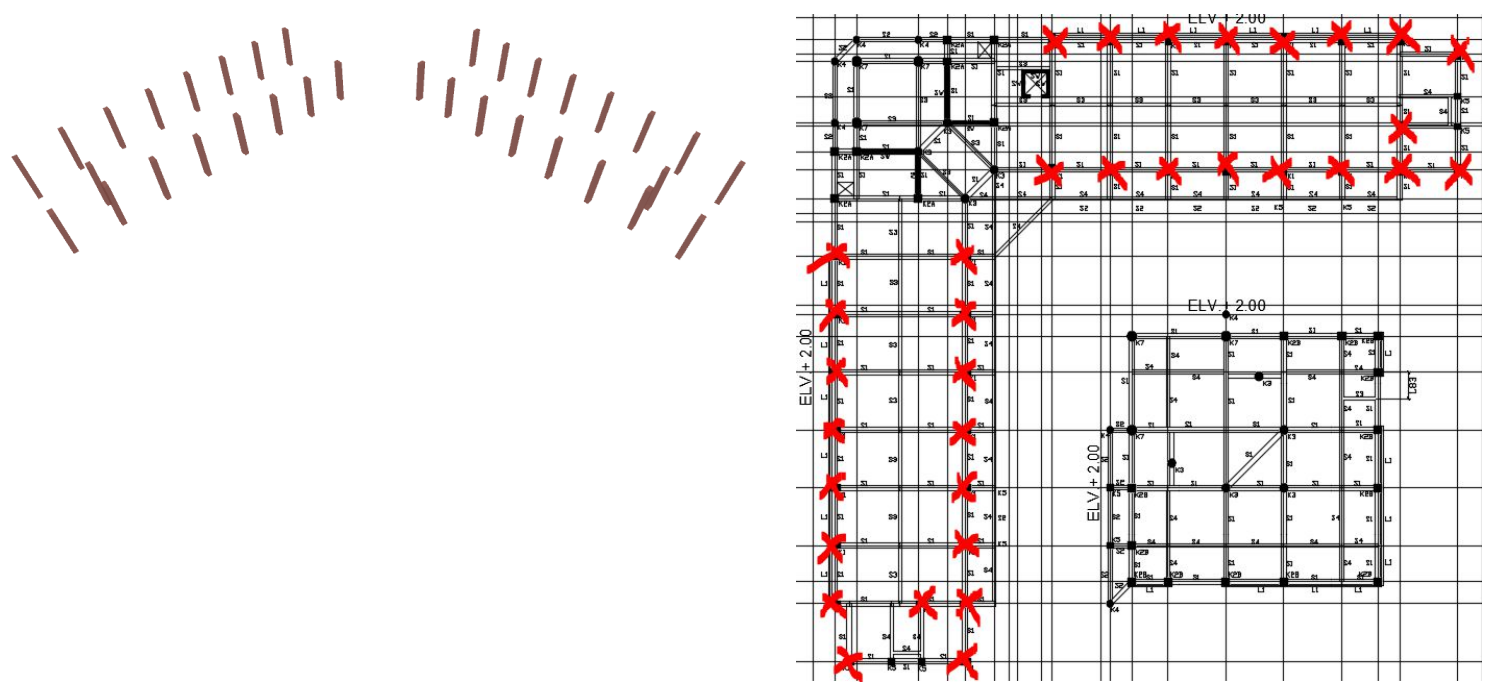

Gambar 14. Kolom K1 (40/70) pada BIM Model
Gambar 15. Denah Lokasi Kolom K1 $(40 / 70)$

\section{KESIMPULAN}

Dalam penelitian ini dilakukan quantity take-off mengunakan software dan dibandingan dengan perhitungan manual dari hasil DED di BoQ proyek. Dari seluruh item pekerjaan arsitektur yang dihitung dengan software sebanyak 146 item pekerjaan, ditemukan 88 pekerjaan sesuai dengan volume manual, 4 pekerjaan hampir sesuai dengan volume manual, 10 pekerjaan tidak sesuai dengan volume manual dan 44 pekerjaan tidak dapat dihitung. Dari seluruh item pekerjaan struktur yang dihitung sebanyak 122 item pekerjaan, ditemukan 113 pekerjaan sesuai dengan volume manual, 2 pekerjaan hampir sesuai dengan volume manual, 6 pekerjaan tidak sesuai dengan volume manual dan 1 pekerjaan tidak dapat dihitung.

Kelebihan penggunaan software software Autodesk ${ }^{\circledR}$ Revit $^{\circledR}$ dan Autodesk ${ }^{\circledR}$ Naviswork ${ }^{\circledR}$ Manage untuk pekerjaan Quantity Take-Off tersebut adalah: Penggunaan software tersebut dapat meminimalisir berbagai kesalahan-kesalahan yang terjadi akibat kesalahan manusia 
seperti item pekerjaan terhitung dua kali, salah penginputan angka, salah ukur, dan lainlain. Hal ini karena perhitungan volume yang dilakukan software selalu berdasarkan data dari objek yang ada pada BIM Model; Penggunaan Fitur Clash Detection untuk mendeteksi kemungkinan benturan antar elemen bangunan sebelum bangunan dibangun. Sehingga kesalahan-kesalahan desain dapat diminimalisir; Perhitungan volume dapat diupdate secara otomotis apabila terjadi perubahan pada BIM Model.

Kekurangan dalam pemakaian software tersebut adalah tingkat keakuratan dalam pekerjaan Quantity Take-Off dipengaruhi oleh tingkat kedetailan BIM Model tersebut. BIM Model yang tidak dimodelkan dengan benar akan memberikan perhitungan volume yang salah. Kemudian penggunaan software yang cukup sulit, membutuhkan kualifikasi keahlian yang tinggi.

\section{DAFTAR PUSTAKA}

Autodesk. (2020). Multidisciplinary BIM software for higher-quality, coordinated designs. https://asean.autodesk.com/products/revit/overview

B1M. (2015). What is a "BIM Model"? https://www.theb1m.com/video/what-is-a-bim-model

Badan Pembinaan Konstruksi Kemen. PU. (2014). Materi Pelatihan Ahli Muda Quantity Surveyor. Depaartemen Pekerjaan Umum.

Bew, M., \& Richards, M. (2008). Bew-Richards BIM maturity model. BuildingSMART Construct IT Autumn Members Meeting.

Firdaus, F., Hidayat, B., \& Istijono, B. (2020). Identifikasi Faktor Penyebab Keterlambatan Pelaksanaan Proyek Infrastruktur Sumberdaya Air di Kabupaten Solok. Jurnal Rekayasa Sipil (JRS-Unand), 16(2), 132-142.

PUPR. (2018). Building Information Modelling (Bim) Dalam Meningkatkan Akuntabilitas Mitra Kerja Kementerian Pekerjaan Umum Dan Perumahan Rakyat (PUPR). Bunga Rampai Knowledge Management Penerapan Teknologi, November-Desember.

Smith, D. K., \& Tardif, M. (2009). Building information modeling: a strategic implementation guide for architects, engineers, constructors, and real estate asset managers. John Wiley \& Sons.

Soedrajat, A. (1984). Analisa (Cara Modern) Anggaran Biaya Pelaksanaan. Nova.

Stachoni, M. (2011). Introducing Navisworks Manage 2011. https://cupdf.com/document/cr422-1introducing-navisworks-manage-2011.html

Wikipedia. (2018). Quantity take-off. https://en.wikipedia.org/wiki/Quantity_take-off 